\title{
Carp - Our Newest Fish
}

By F. MERVYN ATTON

Unwelcome visitors cannot always be turned away. Since 1952, several Saskatchewan waters have been invaded by the carp, Cyprinus carpio. This is an Asiatic fish, introduced first into Europe and then into the United States. Although not esteemed as a food fish on this continent as it is in some parts of Europe, it has become an important commercial species. Our concern with its presence in Saskatchewan comes from its competition with our native fishes.

The mouth of the carp has two pairs of barbels-the second pair, at the corners of the mouth, being most conspicuous. It has no teeth. The body is laterally compressed, robust, and covered with large scales. The color is olive-green above, becoming lighter on the belly. The young are a muddy grey color. At Last Mountain Lake the bigmouth buffalofish (Megastomatobus) has been frequently confused with the carp. The line sketches of the carp (upper) and buffalofish (lower) indicate that the barbels are the important distinguishing feature. In the South Saskatchewan River, fishermen often report capturing carp, but up to the present these fish have always proved to be quillback suckers. The first spine in the dorsal fin of this sucker is much longer and smoother and the body is much more laterally compressed than that of the carp.

In Saskatchewan, carp have been found in the Qu'Appelle River and in the Assiniboine and Swan Rivers. Since they are well established in Lake Winnipeg, they may in the future ascend the Saskatchewan River. They are also in the southwest corner of the province in the Frenchman River, a tributary of the Missouri.

Like the English sparrow among birds and the Norwegian rat among
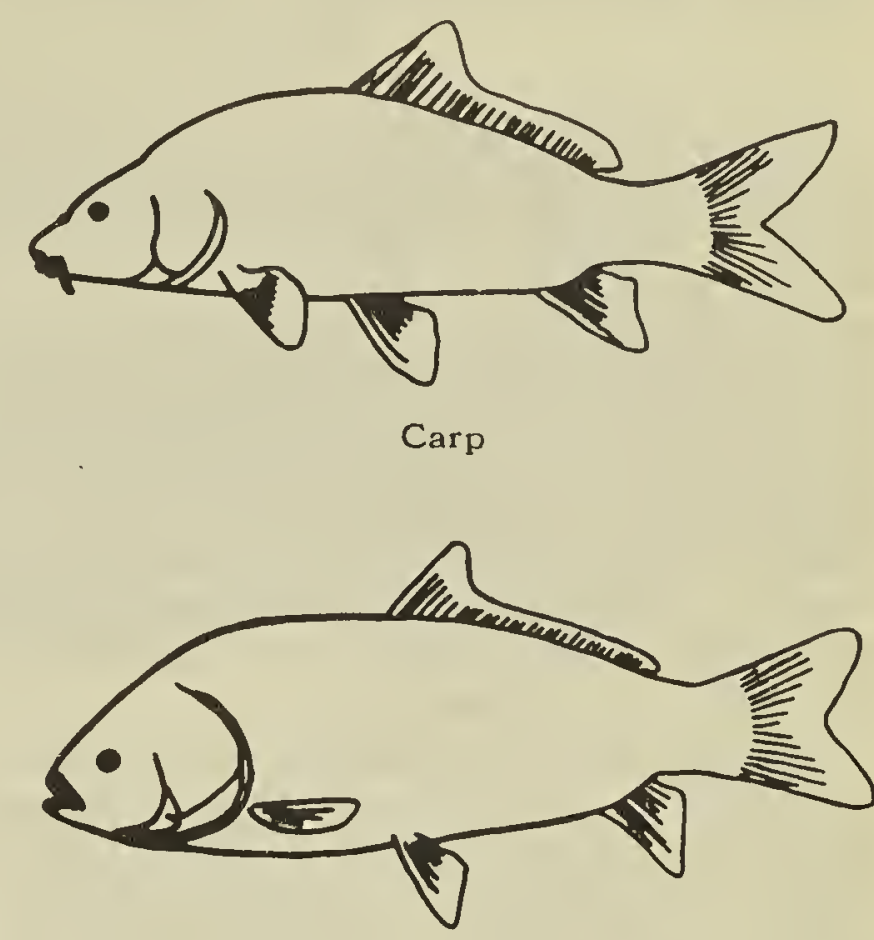

Buffalo Fish

mammals, the carp has proved to be a nuisance, largely because of its feeding habits. Rooting in the bottom ooze not only causes "muddy" water and destroys aquatic vegetation, it also destroys the spawning areas and hiding places of our other fish. The important foods of the carp are aquatic vegetation and insects, snails, crustaceans and mud.

Spawning takes place in June and July in shallow grassy areas of bays and where floodwaters provide suitable depth. The spawning act is sometimes called "rolling" because there is a great deal of splashing and commotion. The adhesive eggs fall to the bottom where they hatch in eight or more days, depending on the temperature. In our waters, young carp captured in October are four to six inches long.

If this fish becomes established in any body of water it will compete with other fishes for food, will destroy their habitat and produce the turbidity which prevents the reestablishment of aquatic plants. If the lake is shallow, wind action will erode the barren shores and prolong the turbidity thus preventing the reestablishment of the beneficial aquatic weeds. The productivity of the lake is generally lowered and desirable species of fish may disappear. 